\title{
A Link Between Platelet-to-Lymphocyte Ratio and Helicobacter pylori Infection
}

\author{
Sergiu Ioan Frandeș1, Oana Chibulcutean², Simona Bățagă \\ 1 Department of Gastroenterology, Faculty of Medicine, “George Emil Palade” University of Medicine, Pharmacy, Science and \\ Technology, Târgu Mureş, Romania \\ 2 Faculty of Medicine, "George Emil Palade” University of Medicine, Pharmacy, Science and Technology, Târgu Mureş, Romania
}

\section{CORRESPONDENCE}

\section{Sergiu loan Frandeș}

Str. Gheorghe Marinescu nr. 38

540139 Tîrgu Mureș, Romania

Tel: +40 265215551

E-mail: sergiu.frandes@yahoo.com

\section{ARTICLE HISTORY}

Received: September 9, 2021

Accepted: September 13, 2021
Oana Chibulcutean • Str. Gheorghe Marinescu nr. 38 540139 Târgu Mureș, Romania. Tel: +40 265215 551, E-mail: oana_chibulcutean@yahoo.com

Simona Bățagă • Str. Gheorghe Marinescu nr. 38, 540139 Târgu Mureș, Romania. Tel: +40 265215 551, E-mail: simonabataga@yahoo.com

\begin{abstract}
Background: Gastritis is a progressive disease that evolves from a non-atrophic to an atrophic state and progresses through intestinal metaplasia, even leading to gastric cancer. Gastritis is defined by an inflammatory process of the mucosal lining of the stomach. Aim: We aimed to identify any association between Helicobacter pylori $(H$. pylori)-positive gastritis and simple inflammatory markers derived from a complete blood count such as the platelet-to-lymphocyte ratio (PLR). Material and Methods: We performed a retrospective case-control study in which we included patients who underwent an upper digestive endoscopy with biopsy between January 2019 and December 2020 and were diagnosed with gastritis. H. pylori status was determined from the histopathological examination, and complete blood count was performed from venous blood samples. The final study group included 125 patients with $\mathrm{H}$. pylori-positive chronic gastritis, and the control group was made up by 207 patients without $H$. pylori infection. Results: We found a higher value of the PLR in $\mathrm{H}$. pylori-positive patients than in the control group, but the difference was not significant statistically. Conclusions: PLR levels could be a predictor of inflammation in H. pylori infection, but an extensive study is needed to confirm this theory.
\end{abstract}

Keywords: Helicobacter pylori, gastritis, platelet-to-lymphocyte ratio

\section{INTRODUCTION}

Helicobacter pylori (H. pylori) is a gram-negative bacterium, with person-to-person transmission, which affects more than 50 percent of the world's population and is one of the most common chronic bacterial infections in humans. ${ }^{1}$ The infection is more frequent in developing countries, and $H$. pylori is a common cause of gastritis or gastric ulcers and gastric cancer. ${ }^{2}$ Diagnostic testing for $H$. pylori can be achieved with invasive and noninvasive techniques. The injuries caused by $H$. pylori to the gastric mucosa are believed to be associated with increased inflammatory markers resulting from the immune response and platelet activation. Some studies have demonstrated a correlation between inflammatory markers and the presence of $H$. pylori infection. ${ }^{3,4}$ Particularly, C-reactive protein levels were observed to increase in $H$. pylori infection. ${ }^{5}$ Indicators of 
platelets activation include an increased mean platelet volume (MPV), platelet distribution width (PDW), and platelet count. Chronic inflammation and platelet activation may increase with the presence of $H$. pylori. ${ }^{5}$

The aim of this study was to identify any association between $H$. pylori-positive gastritis and simple inflammatory markers derived from a complete blood count such as the platelet-to-lymphocyte ratio (PLR).

\section{MATERIAL AND METHODS}

We performed a retrospective case-control study in which we included patients diagnosed with gastritis, who underwent an upper digestive endoscopy and biopsy in the Gastroenterology and Endoscopy Unit of the Emergency Clinical County Hospital of Târgu Mureș, Romania between January 2019 and December 2020. Abdominal pain, retrosternal pain, and heartburn were the main symptoms. The $H$. pylori infection was established from the histopathological examination. For all patients, a complete blood count from peripheral venous blood samples was performed. Exclusion criteria were acute infection, liver or renal failure, upper digestive or lower tract hemorrhage, gastric or duodenal ulcer, malignancy, cirrhosis, other inflammatory diseases, and incomplete data. We collected endoscopy findings, histopathological reports, and laboratory results from medical records. Variables including age, gender, endoscopy aspects, morpho-pathological characteristics, and biologic parameters were analyzed. The final study group consisted of 125 patients with $H$. pylori-positive chronic gastritis, and the control group was made up by 207 patients without $H$. pylori infection.

Statistical analysis was performed with Microsoft Excel and GraphPad statistical software. Grubb's test was applied to detect outliers. The Mann-Whitney test was used to compare independent groups, for continuous variables with non-parametric distribution. The $\mathrm{Chi}^{2}$ and Fisher tests were applied to analyze the association between the two groups in regards to quantitative data. The statistical significance level of the study was set at an $\alpha=0.05$.

The study was conducted in accordance with the principles stipulated in the Declaration of Helsinki. All subjects agreed with processing of their data, and the study procedures were carried out following approval of the institution where the patients were treated.

\section{RESULTS}

From the total of 332 cases, 125 (38\%) were H. pylori-positive and 207 (62\%) were $H$. pylori-negative. Table 1 presents the endoscopic and paraclinical characteristics of the study groups.

There were no statistically significant differences between the groups regarding the distribution of genders (60\% females in the $H$. pylori-positive group vs. $68.6 \%$ females in the H. pylori-negative group, $\mathrm{p}=0.1106)$. The mean age was 57.6 years in the $H$. pylori-positive group and 58.4 years in the H. pylori-negative group ( $\mathrm{p}>0.05$ ).

Erythematous aspect of the gastric mucosa was the most frequent endoscopic aspect in both groups $(83.2 \%$ in the $H$. pylori-positive group and $83.09 \%$ in the $H$. pylori-negative group, $\mathrm{p}>0.05)$. Patients with positive $H$. pylori infection had a higher mean of PLR, but the difference did not reach statistical significance (138.69 \pm 47.98 vs. $136.58 \pm 67.56, p$ $=0.753)$. Regarding the absolute number of platelets, there were no significant differences between the two groups ( $H$. pylori-positive group: $268.00 \pm 86.44 \times 10^{9} / \mathrm{L}$ vs. $H$. pylorinegative group: $257.00 \pm 70.41 \times 10^{9} / \mathrm{L}, \mathrm{p}=0.117$ ).

\section{DISCUSSIONS}

H. pylori is considered an independent carcinogen for gastric cancer, ${ }^{6}$ with an increased risk for gastric ma-

TABLE 1. Endoscopic and paraclinical characteristics of the study groups

\begin{tabular}{lccccc}
\hline & \multicolumn{2}{c}{$\begin{array}{c}\text { Helicobacter pylori- } \\
\text { positive gastritis }\end{array}$} & $\begin{array}{c}\text { Helicobacter pylori- } \\
\text { negative gastritis }\end{array}$ & p value \\
\cline { 2 - 5 } & $\mathbf{n}=\mathbf{1 2 5}$ & $\%$ & $\mathbf{n}=\mathbf{2 0 7}$ & \% \\
\hline Females & 75 & 60.00 & 142 & 68.60 & 0.1 \\
Males & 50 & 50.00 & 65 & 31.40 & 0.06 \\
Mean age, years & 56.7 & - & 58.4 & - & 0.05 \\
Erythematous gastritis & 104 & 83.20 & 172 & 83.09 & $<0.05$ \\
PLR* & 136.58 & - & 138.69 & - & 0.7 \\
Platelet count $(\times 109 / \mathrm{L})$ & 268.00 & - & 257.00 & - & 0.1 \\
\hline
\end{tabular}

PLR, platelet-to-lymphocyte ratio 
lignancy of up to four times, and is a common cause of gastric and duodenal ulcers. ${ }^{7,8} \mathrm{H}$. pylori also causes gastritis, an inflammation of the stomach lining, which can lead to chronic inflammation of the gastric cells. Chronic gastritis can lead to gastric atrophy, intestinal metaplasia, and in the last stage, gastric cancer. Recent studies have shown that the absolute number of platelets and the PLR can be used as prognostic factors in different pathologies including inflammatory diseases, cardiovascular disease, or malignancy. Systemic inflammation is associated with changes in blood cells such as increased neutrophils, platelets, and MPV. ${ }^{9-11}$

PLR is a simple inflammatory marker derived from the complete blood count. Previous studies have shown that the PLR was significantly higher in $H$. pylori-positive than in $H$. pylori-negative patients, ${ }^{7}$ while other studies have disproved this finding. ${ }^{12,13}$ In our study, we found higher PLR values in $H$. pylori-positive patients compared to patients presenting with gastritis but with negative testing for this frequent gastrointestinal infectious agent. Also, we observed that the number of platelets were increased in patients with $H$. pylori infection.

Our study has several limitations, including the fact that it was performed only in patients with gastritis who underwent endoscopic examination. Also, the retrospective design of the study made it difficult to have a detailed patient history, and being a single-center study with a relatively small number of patients reduces the possibility to extrapolate the results to a larger population.

\section{CONCLUSIONS}

Even though the values of the platelet-to-lymphocyte ratio were higher in the study group, we did not find a positive association between the platelet-to-lymphocyte ratio and
Helicobacter pylori infection. This parameter could be an indicator of Helicobacter pylori infection, but further studies are needed on larger populations to confirm this hypothesis.

\section{CONFLICT OF INTEREST}

Nothing to declare.

\section{REFERENCES}

1. Pounder RE, Ng D. The prevalence of Helicobacter pylori infection in different countries. Aliment Pharmacol Ther. 1995;9(S2):33-39.

2. Malfertheiner P, Megraud F, O'Morain C, et al. Current concepts in the management of Helicobacter pylori infection: the Maastricht III Consensus Report. Gut. 2007;56:772-781.

3. Kalia N, Jacob S, Brown NJ, Reed MW, Morton D, Bardhan KD. Studies on the gastric mucosal microcirculation. 2. Helicobacter pylori water soluble extracts induce platelet aggregation in the gastric mucosa microcirculation in vivo. Gut. 1997;41:748-752.

4. Elizalde JI, Gomez J, Panes J, et al. Platelet activation in mice and human Helicobacter pylori infection. J Clin Invest. 1997;100:996-1005.

5. Jha HC, Prasad J, Mittal A. High immunoglobulin A seropositivity for combined Chlamydia pneumoniae, Helicobacter pylori infection, and highsensitivity C-reactive protein in coronary artery disease patients in India can serve as atherosclerotic marker. Heart Vessels. 2008;23:390-396.

6. Liu KS, Wong IO, Leung WK. Helicobacter pylori associated gastric intestinal metaplasia: Treatment and surveillance. World J Gastroenterol. 2016;22:1311-1320

7. Farah R, Hamza H, Khamisy-Farah R. A link between platelet to lymphocyte ratio and Helicobacter pylori infection. J Clin Lab Anal. 2018;32:e22222.

8. Perry S, de la Luz Sanchez M, Yang S, et al. Gastroenteritis and transmission of Helicobacter pylori infection in households. Emerg Infect Dis. 2006:12:1701-1708

9. Topal F, Karaman K, Akbulut S, et al. The relationship between mean platelet volume levels and the inflammation in Helicobacter pylori gastritis. J Natl Med Assoc. 2010;102:726-730

10. Yasui S, Takata T, Kamitani $Y$ et al. Neutrophil-to-Lymphocyte Ratio Is a Useful Marker for Predicting Histological Types of Early Gastric Cancer. J Clin Med. 2021:10:791.

11. Mae Y, Takata T, Ida A, et al. Prognostic Value of Neutrophil-To-Lymphocyte Ratio and Platelet-To-Lymphocyte Ratio for Renal Outcomes in Patients with Rapidly Progressive Glomerulonephritis. J Clin Med. 2020;9:1128.

12. Guclu M, Faruq Agan A. Association of Severity of Helicobacter pylori Infection with Peripheral Blood Neutrophil to Lymphocyte Ratio and Mean Platelet Volume. Euroasian J Hepatogastroenterol. 2017;7:11-16.

13. Kim TJ, Pyo JH, Lee H, et al. Lack of Association between Helicobacter pylori Infection and Various Markers of Systemic Inflammation in Asymptomatic Adults. Korean J Gastroenterol. 2018;72:21-27. 